\title{
Research on the application of palm mat geotextile in sand fixation of the Hobq Desert
}

\author{
Shuai Zhong ${ }^{1,2}$, Zhiwen $\operatorname{Han}^{1 * 1}$, Aimin $\mathrm{Li}^{1,2,3}$, Heqiang $\mathrm{Du}^{1}$ \\ 1 Northwest Institute of Eco-Environment and Resources, CAS, Lanzhou 730000, China; Key Laboratory of \\ Desert and Desertification, CAS, Lanzhou 730000, China; \\ 2. University of Chinese Academy of Sciences, Beijing 100049, China; \\ 3. Resources and Environment Department, Heze University, Heze 274015, China
}

\begin{abstract}
As the traditional sand fixation measures have many limitations, new sand fixing technologies and methods are urgently needed to be developed. This study demonstrated a new sand fixation method using palm mat geotextile to fix the sand dunes and plant grass. We experimented the physical property of the palm mat geotextile in the laboratory, and observed the vegetation growth in the Hobq Desert. The results showed that (1)The palm mat geotextile is more lighter and tougher than the common straw mat geotextile, the average weight, thickness and tensile strength of palm mat geotextile were $2023 \mathrm{~g} / \mathrm{m}^{2}, 20.14 \mathrm{~mm}$, and $842-860 \mathrm{~N} / \mathrm{m}$, after a year of field observation, the tensile strength decreased by only $2 \%$. (2) The palm mat geotextile had excellent water retention capacity and scouring resistance, the maximum water content reached $227 \%$, and the substrate lost $2.9 \%$ after the simulation of heavy rainfall for 3 hours with rainfall intensity of $30 \mathrm{~mm} / \mathrm{h}$ in laboratory. (3) The palm mat geotextile significantly decreased the soil temperature and increase the humidity in summer, the observed results shown that the palm mat geotextile had the greatest influence on $5 \mathrm{~cm}$ depth of the soil temperature and $10 \mathrm{~cm}$ depth of soil humidity. (4) The field experiment results showed that the vegetation coverage and the biomass of the palm mat geotextile with $2 \mathrm{~m} \times 2 \mathrm{~m}$ were $35 \%$ and $11.21 \mathrm{~g}$ (3.9 times and 4.1 times than that of control group, 1.7 times and 1.8 times than that of high-banded salix psammophila sand-barriers group which is widely used in the Hobq Desert).
\end{abstract}

Keywords: Growth promotion; Palm mat geotextile; Physical property; Sand fixation

*Corresponding author: Han Zhiwen (E-mail: hzwen@lzb.ac.cn) 


\section{Introduction}

As the definition given by the United Nations Convention to Combat Desertification (UNCCD), desertification refers to the land degradation in arid, semi-arid and dry sub-humid areas resulting from various factors including climatic variations and human activities ${ }^{[1]}$.Desertification is a very serious environmental and socio-economic problem facing the world, Globally desertified land amounts to $3.6 \times 10^{7} \mathrm{~km}^{2}$, covers $24.1 \%$ of Earth's land surface expanding at the rate of $6 \times 10^{4} \mathrm{~km}^{2}$ per year and affects about one-sixth of the world's population, many of whom live in poverty ${ }^{[2]}$. China is one of the most serious desertification countries in the world, the desertification area covered $1.72 \times 10^{6} \mathrm{~km}^{2}$, involving 30 provinces (regions), which accounted for about $17.93 \%$ of the territory area by the end of $2014^{[3]}$. There are several major types of desertification including sandy desertification, soil and water erosion, and salinization $^{[4]}$. Sandy desertification or aeolian desertification ${ }^{[5]}$ is the most severe issue among all types of desertification in Northern China where the fragility of the ecosystems is predetermined by inherently harsh physical conditions, such as sparse vegetation, continental climate, sandy soils and water deficiency ${ }^{[6-8]}$. Sand fixation is one of the major measures in sandy desertification control.

Generally speaking, there are three kinds of sand-fixation techniques, engineering sand-fixation technique, biological sand-fixation technique and chemical sand-fixation technique. Engineering sand-fixation technique uses branches ${ }^{[9]}$ plant straw ${ }^{[10]}$ and grave ${ }^{[11-12]}$ et al. to set up barriers to fix the sand dunes, and later adding in nenolen net ${ }^{[13]}$, HDPE net ${ }^{[14]}$ and environmental plant fiber net et al. Biological sand fixation technique fixes the sand dunes by planting vegetation ${ }^{[15-16]}$, which is economical, persistent, and effective method, but it is very difficult to build in the early stage of desertification control ${ }^{[17-19]}$. Chemical sand fixing technique sprays chemically bonded materials on the sand dunes to form a consolidation layer to prevent the wind erosion ${ }^{[20]}$,but the cost of material is relatively high ${ }^{[21]}$. In recent years, although some progress has been made in sand fixation around the world, there are still many problems to be solved, for example, the slow development of the new 
technology and new materials.

Straw mat geotextile sand-fixation technique combines engineering sand-fixation technique and biological sand-fixation technique, which uses straw fabrics as the carrier, containing seeds (trees, shrubs, grass) and nutrient soil, fixed by fabric net finally ${ }^{[22-24]}$. Straw mat geotextile is widely used in landscaping, road, railway, reservoir, river embankment and other slope greening protection ${ }^{[25-29]}$.

Palm mat geotextile is one of the excellent straw mat geotextile. Palm fiber is strong, wear-resistant, breathable, light, corrosion resistant and elastic as a new type of natural fiber began to be used in all fields. Palm-mat geotextiles was used for rainsplash erosion control ${ }^{[30]}$.Palm mat geotextile was applied in the conservation of loamy sand soils in east Shropshire, $\mathrm{UK}^{[31]}$. Palm and simulated geotextiles was used in reducing run-off and inter-rill erosion on medium and steep slopes ${ }^{[32]}$.

However, there is no report about palm mat geotextile used as sand fixation measure in the desert. To bridge this gap, we experimented palm mat geotextile to fix the sand dunes in the Hobq Desert. Hobq Desert covering about $1.45 \times 10^{4} \mathrm{~km}^{2}$ is the seventh largest desert in China, which located in the north of Ordos Plateau. it is one of the important sandstorm source threatening the Beijing ,Tianjin and Hebei urban region where the linear distance from the Hobq Desert is about $800 \mathrm{~km}$. Moreover, in the eastern part of the Hobq Desert, ten tributaries of the Yellow River cross the desert, and these are called the Ten Tributaries. According to the research results ${ }^{[33]}$, the annual sediment by floods through the Ten Tributaries could reach as high as $0.237 \times$ $10^{8}$ tons, the sediment causes serious silting in the Yellow River. Therefore, it is very urgent to control the sandy desertification of Hobq Desert.

the objective of this study was to evaluate the effect of sand fixation of palm mat geotextile, compare with the traditional sand fixation measures and find a new cheap, environmental and more suitable sand fixation material for the sandy desertification control in the Hobq Desert.

\section{Materials and methods}

\subsection{Material}


The palm mat geotextile uses palm fiber as the carrier, and contains a variety of materials including seeds (shrubs, grass), nutrient soil, non-woven fabric and fixed net. The materials, specifications and structure of the palm mat geotextile showed in table $1,2,3$ and figure 1.

Table 1. Materials of the palm mat geotextile

\begin{tabular}{ccc}
\hline Types & Materials & Specifications \\
\hline Raw material & Palm fiber & $15 \mathrm{~cm}-25 \mathrm{~cm}$ \\
Cushion & Non-woven fabric & $100 \mathrm{~g} / \mathrm{m}^{2}$ \\
Fixed net & Polypropylene $(\mathrm{PP})$ & $5 \mathrm{~mm} \times 5 \mathrm{~mm}$ \\
Sewing thread & Polypropylene $(\mathrm{PP})$ & $\mathrm{d} \geq 0.3 \mathrm{~mm}$ \\
\hline
\end{tabular}

Table 2. Index of the seeds

\begin{tabular}{cccc}
\hline Types & $\begin{array}{c}\text { Germination rate } \\
/ \%\end{array}$ & $\begin{array}{c}\text { Thousand kernel } \\
\text { weight } / \mathrm{g}\end{array}$ & neatness /\% \\
\hline Agriophyllum squarrosum & 79.77 & 0.92 & 92.75 \\
Artemisia desertorum & 81.35 & 0.86 & 89.73 \\
Hedysarum mongdicum & 67.67 & 27.44 & 91.62 \\
Hedysarum scoparium & 72.33 & 16.35 & 93.47 \\
\hline
\end{tabular}

Table 3. Index of the soil

\begin{tabular}{cccccccccc}
\hline $\mathrm{pH}$ & $\mathrm{CO}_{3}^{2-}$ & $\mathrm{SO}_{4}^{2-}$ & $\mathrm{CL}^{-}$ & $\mathrm{HCO}_{3-}$ & $\mathrm{Ca}^{2+}$ & $\mathrm{N}$ & $\mathrm{P}$ & \multicolumn{2}{c}{ Organic matter } \\
& $\%$ & $\%$ & $\%$ & $\%$ & $\%$ & $\%$ & $\%$ & $\%$ & $\%$ \\
\hline 7.85 & 6.63 & 0.43 & 0.02 & 0.02 & 0.07 & 0.53 & 0.21 & 0.78 & 15.79 \\
\hline
\end{tabular}

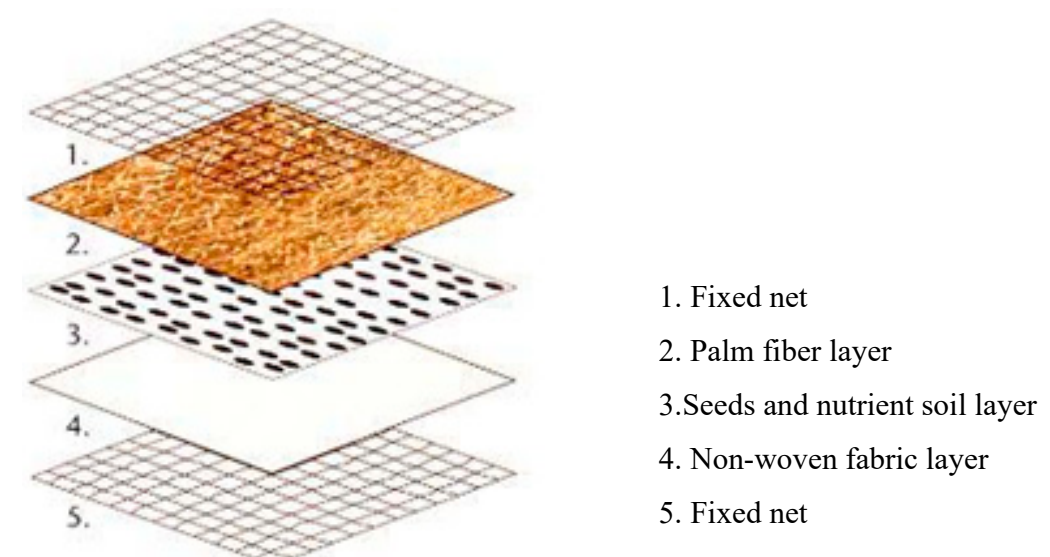

Fig.1 Structure of the palm mat geotextile 


\subsection{Physical performance test of the palm mat geotextile in the lab}

The quality, thickness and tensile strength of the palm mat geotextile are important mechanical indexes for the application. The water permeability and saturated water content of the palm mat geotextile is good for the infiltration and storage of the rainwater, which affects the vegetation growth. Three pieces of palm mat geotextile with $1 \mathrm{~m}^{2}$ were randomly selected from the product, the average quality measured by electronic balance (produced by A\&D company, Japan, precision with $0.01 \mathrm{~g}$ ), and the average thickness measured by the electronic vernier caliper (produced by Mitutoyo company, Japan, precision with $0.01 \mathrm{~mm}$ ). Tensile strength measured by electronic wire strength tester (produced by Sansi electromechanical company China, precision with $1 \mathrm{~N} / \mathrm{m}$ ) sampling from the field every three months. Three pieces of palm mat geotextile with $100 \mathrm{~cm}^{2}$ were randomly selected from the product to observe and measure the water permeability, saturated water content and structure stability. The quality difference of the palm mat geotextile before and after adequately soaking in the water was saturated water content. Water permeability and structure stability were observed through the simulated rainfall spraying in the lab. The carpet weight was measured every thirty minutes during Simulated the extreme rainfall for 3 hours with $30 \mathrm{~mm} / \mathrm{h}$.(According to the local meteorological data in recent three years, the intensity of precipitation was not more than 2 hours with $20 \mathrm{~mm} / \mathrm{h}$ ).

\subsection{Field experiment}

\subsubsection{Location of the experimental site}

Experiment field was located in the north of the Hobq Desert, the geographical coordinates $\left(108^{\circ} 42^{\prime} 28.13^{\prime \prime} \mathrm{E}, 40^{\circ} 29^{\prime} 49.70^{\prime \prime N}\right)$.(Fig2). It is typical temperate continental arid monsoon climate with cold winter and hot summer. The annual average temperature is $6 \sim 7.5^{\circ} \mathrm{C}$, the lowest and highest temperature is $-32.1^{\circ} \mathrm{C}$ in January and $38.7^{\circ} \mathrm{C}$ in July. The annual precipitation is 150 to $400 \mathrm{~mm}$ with $70 \%-80 \%$ falling in July to September, but the annual evaporation reaches 2100 to $2700 \mathrm{~mm}$. The annual average and maximum wind velocity is $3.5 \mathrm{~ms}^{-1}$ and $16.6 \mathrm{~ms}^{-1}$, the main sand wind direction are easterly wind (ENE and E, 116.22 VU) and westerly wind 
(SW, WSW, W, WNW and NW, 104.71 VU) The field experiment began in June 2016 for one year.

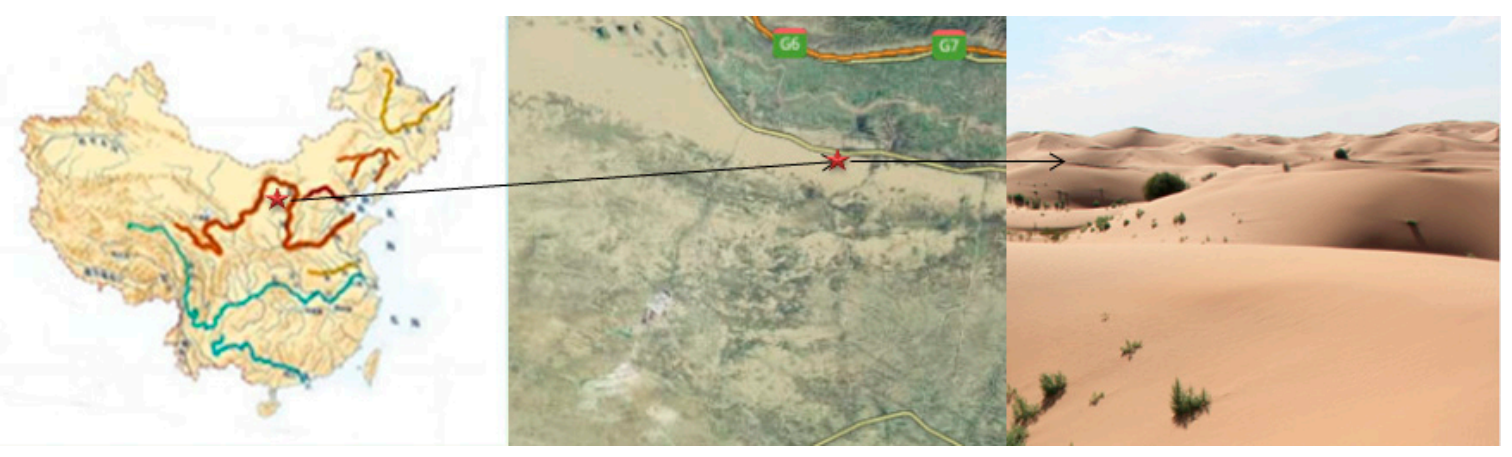

Fig.2 Location of the study site and ground condition

\subsubsection{Experimental setting}

we set the palm mat geotextile group, high-banded salix psammophila sand-barriers group and control group which was the same with $1500 \mathrm{~m}^{2}$. To estimate the advances of palm grass carpet we set high-banded salix psammophila sand-barriers experiment as contrast, for it is one of the common and effective sand fixation measures in Hobq desert. The height and specification of high-banded salix psammophila sand-barriers was $20 \mathrm{~cm}$ and $1 \mathrm{~m} \times 1 \mathrm{~m}$, the permeability was less than $5 \%$. The amount of sowing seeds of high-banded salix psammophila sand-barriers group and the control group were the same with palm mat geotextile group.

The soil temperature and humidity directly affect the sprouting and growth of plants. Thus, $0 \sim 5 \mathrm{~cm}, 5 \mathrm{~cm} \sim 10 \mathrm{~cm}, 10 \mathrm{~cm} \sim 15 \mathrm{~cm}, 15 \mathrm{~cm} \sim 20 \mathrm{~cm}$ of the soil temperature and $10 \mathrm{~cm}, 20 \mathrm{~cm}, 30 \mathrm{~cm}$ of the soil humidity were continuously recorded by the desert weather station(produced by sunshine meteorological science and technology company, China, precision with $0.01{ }^{\circ} \mathrm{C}$ ). to recognize the change of soil temperature and humidity.

Three samples $(1 \mathrm{~m} \times 1 \mathrm{~m})$ were randomly selected and fixed from each group, and continuously observed the plants growth. The preservation number of plants was recorded every month. The samples photos were taken every 3 months and the vegetation pixel was selected by Adobe Photoshop to calculate vegetation coverage. At the end of the experiment, all the plants according to the groups were picked up, 
dried by the drying Oven and weighed up to calculate the biomass.

\section{Results}

\subsection{Physical performance of the palm mat geotextile}

The average weight, thickness and tensile strength of the palm mat geotextile were $2023 \mathrm{~g} / \mathrm{m}^{2}, 20.14 \mathrm{~mm}$ and $860 \mathrm{~N} / \mathrm{m}$. The tensile strength decreased by only $2 \%$ one year later. (Fig 3) During the experimental period, the palm mat geotextile fixed sand dunes completely and without any breakage. While the average weight, thickness and tensile strength of normal straw mat geotextile are $2500-3000 \mathrm{~g} / \mathrm{m}^{2}, 25-30 \mathrm{~mm}$ and $300-350 \mathrm{~N} / \mathrm{m}^{[34]}$, therefore palm mat geotextile is more light, tough and durable.

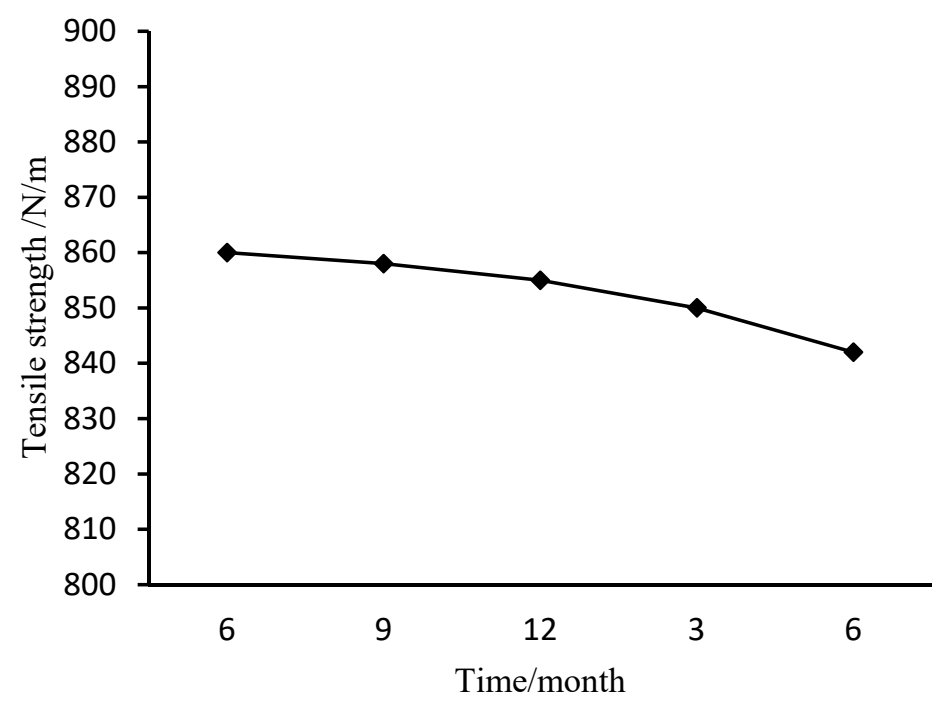

Fig.3 Tensile strength of the palm mat geotextile

\subsection{Water permeability, saturated water content and structure stability}

The results of the immersion experiment showed that the initial and after immersion quality of the $100 \mathrm{~cm}^{2}$ palm mat geotextile were $20.11 \mathrm{~g}$ and $65.78 \mathrm{~g}$, the water content reached $227 \%$, While the water content of normal straw mat geotextile is $70 \%-120 \%{ }^{[34]}$,indicating that the palm mat geotextile had excellent water permeability and retention. The results of artificial simulated precipitation scour test showed that the substrate loss increased with the precipitation time in the first $1.5 \mathrm{~h}$, and the substrate loss was very small after $1.5 \mathrm{~h}$. The total loss rate was $2.9 \%$. In general, The palm mat geotextile had good stability after the heavy rain (Fig 4). 


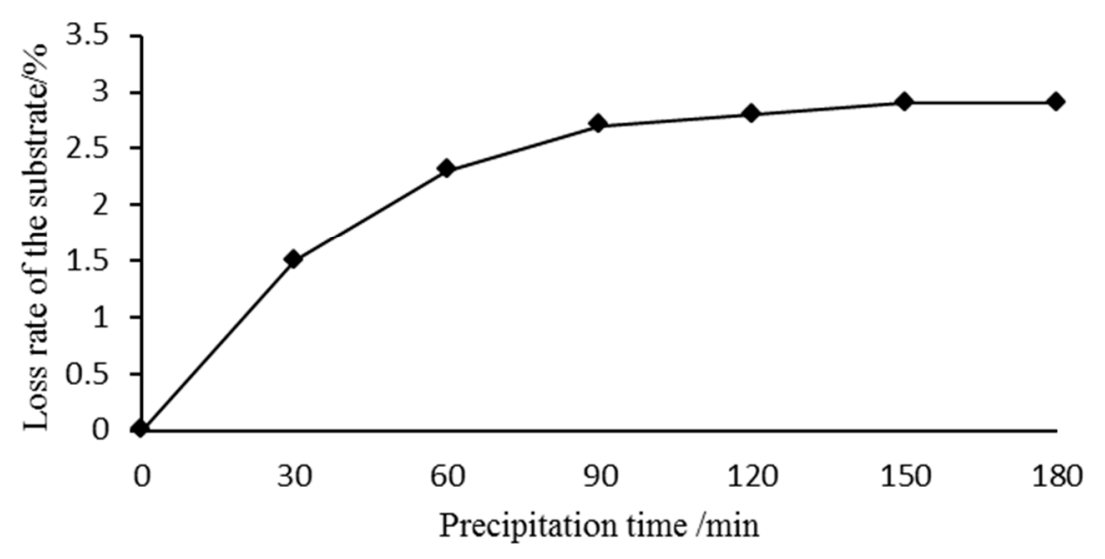

Fig.4 The loss rate of the substrate

\subsection{Effects of the palm mat geotextile on soil temperature}

The palm mat geotextile had great impact on soil temperature in $0 \sim 5 \mathrm{~cm}$ depth, the deeper the soil, the smaller the influence. The soil temperature in $0 \sim 5 \mathrm{~cm}$ depth was $7.5^{\circ} \mathrm{C}(29.4 \%)$ lower than the control group in July, and $1.3^{\circ} \mathrm{C}$ higher than the control group in November. Besides, little difference of temperature curve existed between the high-banded salix psammophila sand-barriers and the control group (Fig. 5). Therefore, the palm mat geotextile had cooling effect in summer, heat preservation in winter, which can effectively prevent the plant from being damaged by the high temperature of the ground. The high-banded salix psammophila sand-barriers had little influence on the soil temperature. 

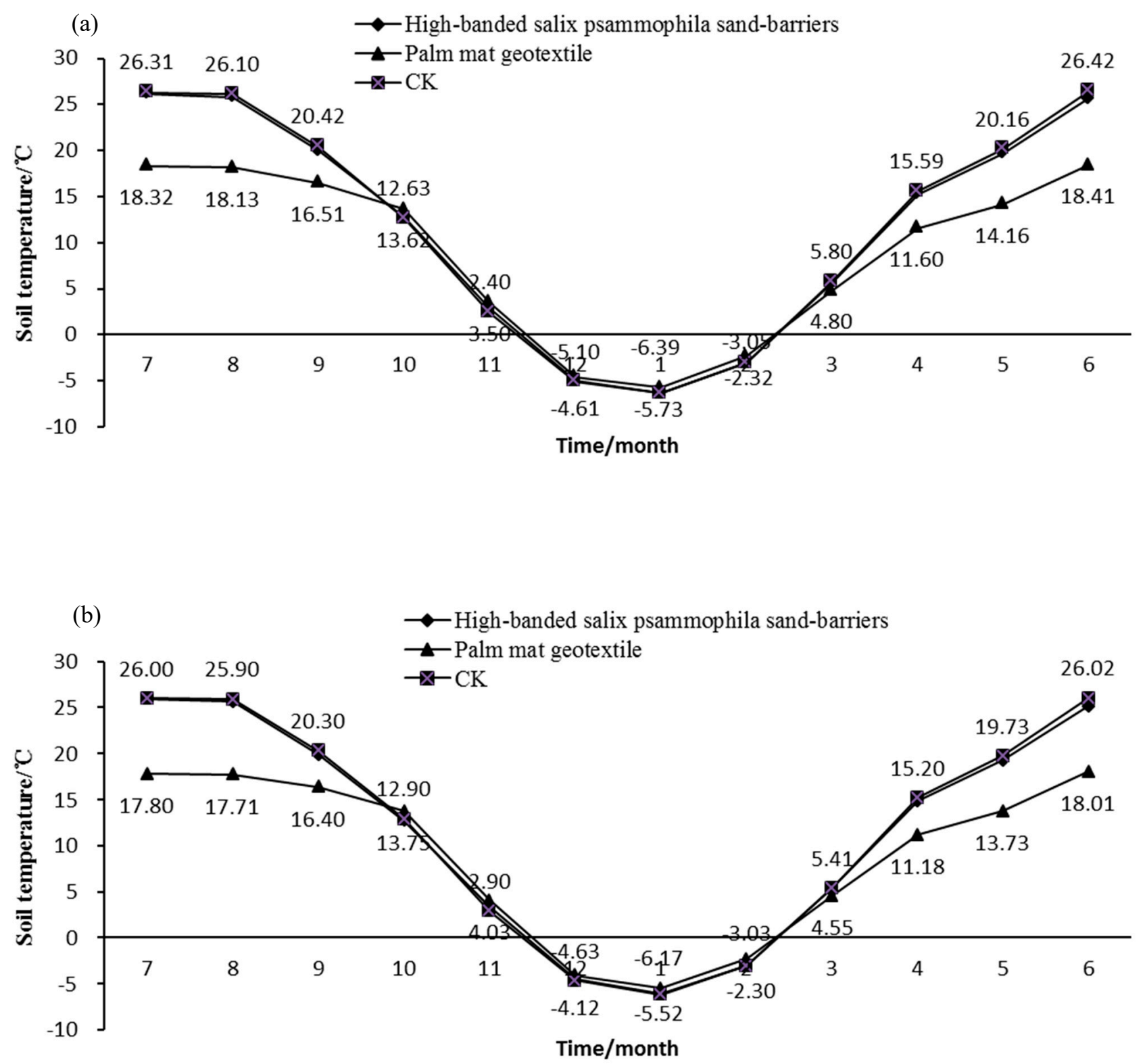
(c)
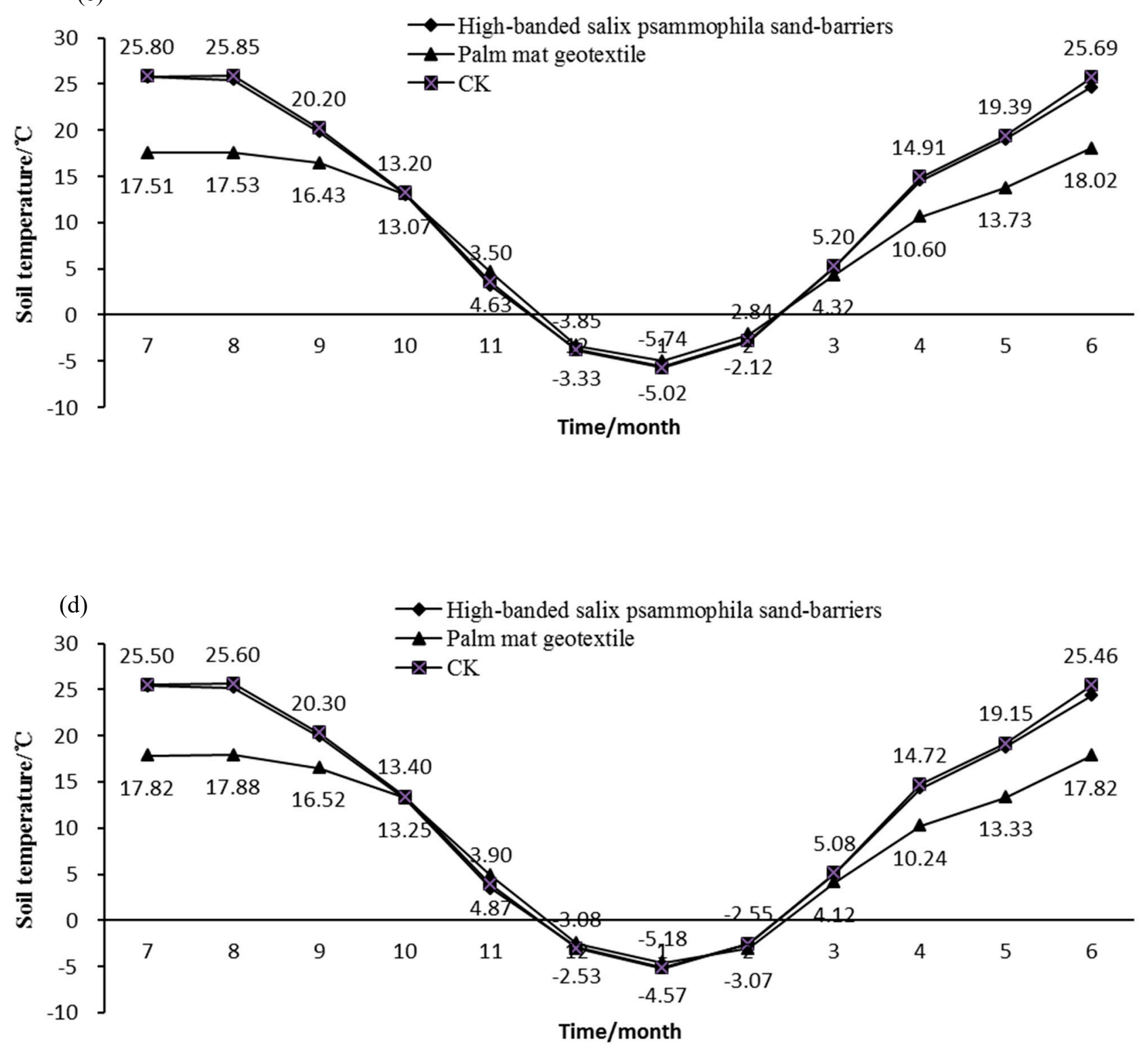

Fig. 5 The soil temperature (a) $0 \sim 5 \mathrm{~cm} \quad$ (b) $5 \mathrm{~cm} \sim 10 \mathrm{~cm} \quad$ (c) $10 \mathrm{~cm} \sim 15 \mathrm{~cm} \quad$ (d) $15 \mathrm{~cm} \sim 20 \mathrm{~cm}$

\subsection{Effects of the palm mat geotextile on soil humidity}

The palm mat geotextile had great impact on soil humidity in $10 \mathrm{~cm}$ depth, the deeper the soil, the smaller the influence. The soil humidity of the palm mat geotextile in $10 \mathrm{~cm}$ depth was 2.9 times than the control group and 3.5 times than the high-banded salix psammophila sand-barriers group in August.(Fig. 6). Therefore, palm mat geotextile could significantly improve the soil humidity. The soil humidity of the 
high-banded salix psammophila sand-barriers group was slightly smaller than the control group, because the more plants in the high-banded salix psammophila sand-barriers group grew, the more evaporation channels formed in the soil.
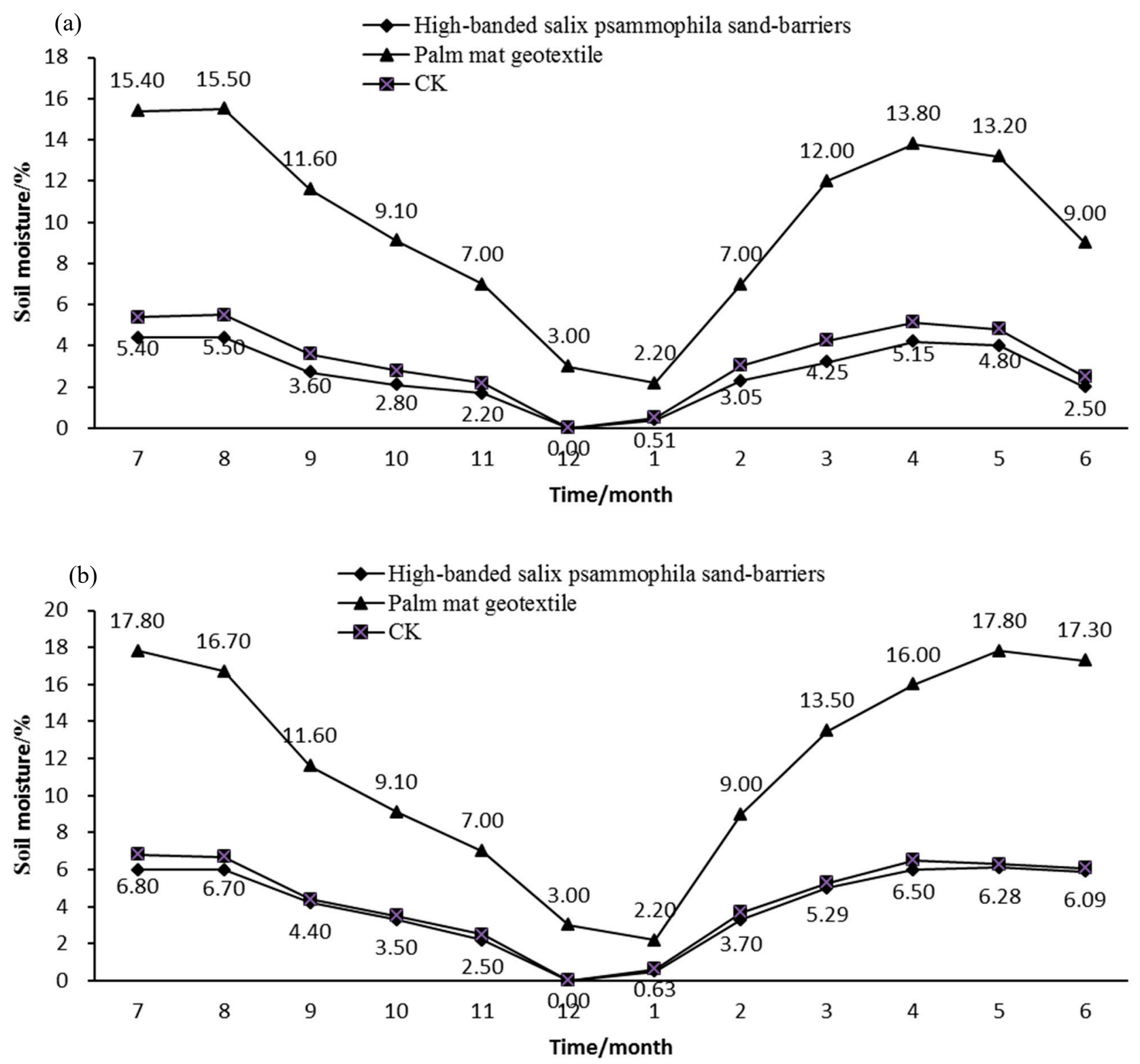


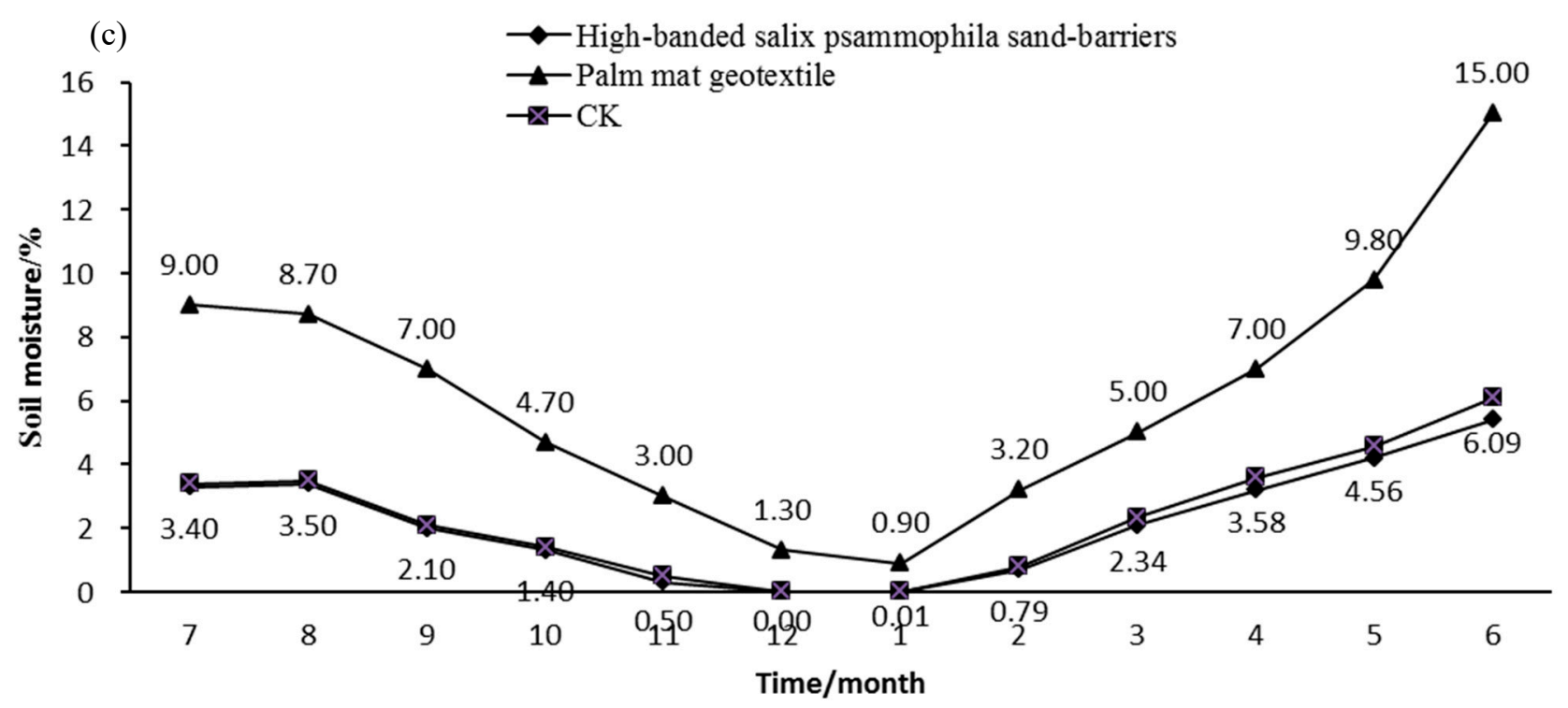

Fig.6 The soil humidity (a) $10 \mathrm{~cm} \quad$ (b) $20 \mathrm{~cm} \quad$ (c) $30 \mathrm{~cm}$

\subsection{Effects of the palm mat geotextile on plant growth}

The practicability of the palm mat geotextile largely depends on vegetation restoration effect. The emergence rates of the palm mat geotextile group, high-banded salix psammophila sand-barriers and control group were $24 \%, 55 \%$ and $41 \%$ (Fig. 7 a). The palm mat geotextile and high-banded salix psammophila sand-barriers had certain wind erosion resistance, but thickness of the palm mat geotextile influenced its emergence rate.

The seeding number of the palm mat geotextile group, high-banded salix psammophila sand-barriers group and control group were 36, 93 and 75 in July. Because of the high temperature, drought and wind erosion, the seeding number of the high-banded salix psammophila sand-barriers group and control group sharply decreased, but the palm mat geotextile group increased from July to November. The seeding number of three groups decreased in different degrees from November to May of the following year. The number of seedlings of the three groups increased after May of the following year, and the palm mat geotextile group was the most with 25 (3.6 times than the control group and 1.5 times than the high-banded salix psammophila sand-barriers group) (Fig. 7b).

The vegetation coverage and biomass of the palm mat geotextile group were $35 \%$ and 
13.2 g, which were 3.9 and 4.1 times than that of the control group, 1.7 and 1.8 times than that of the high-banded salix psammophila sand-barriers group (Fig. 7c,d). Moreover, the vegetation type of the palm mat geotextile and high-banded salix psammophila sand-barriers were mainly Artemisia Artemisia and Agriophyllum squarrosum (Fig. 8). Thus, the palm mat geotextile had the most important protective effects on the vegetation growth, the high-banded salix psammophila sand-barriers followed.
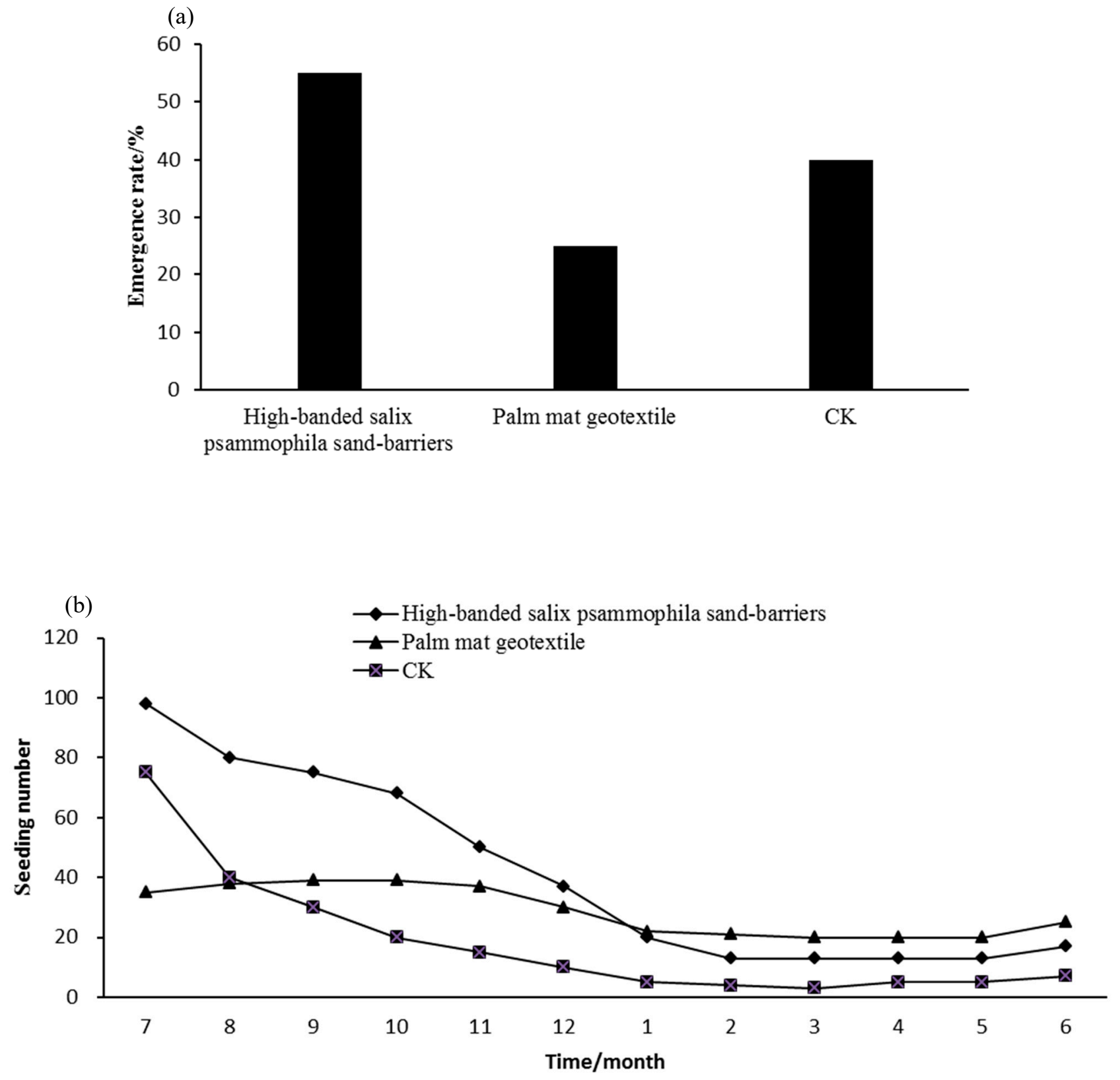

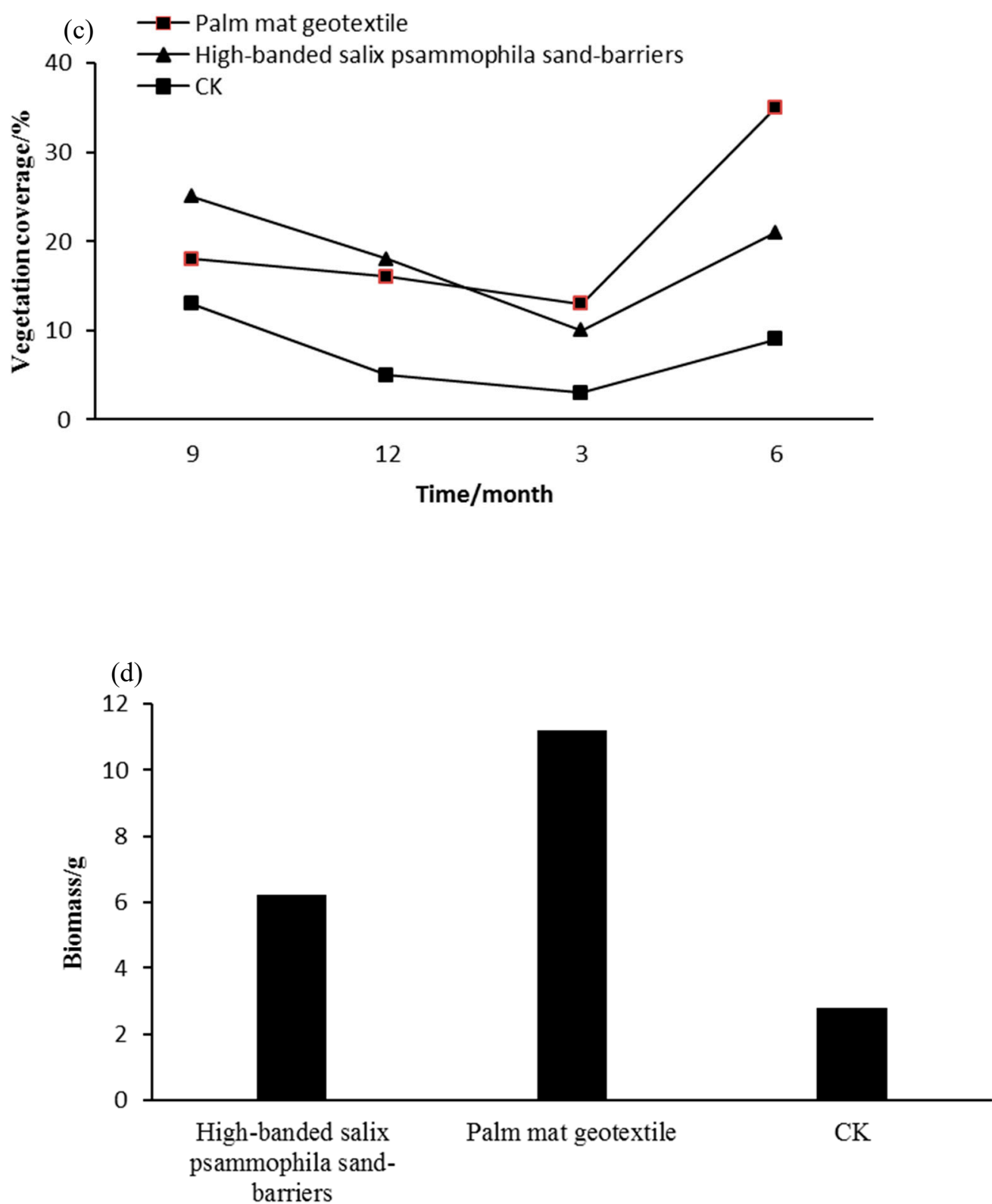

Fig.7 Index of the plants growth (a) Emergence rate (b) Seeding number (c) Vegetation coverage (d) Biomass

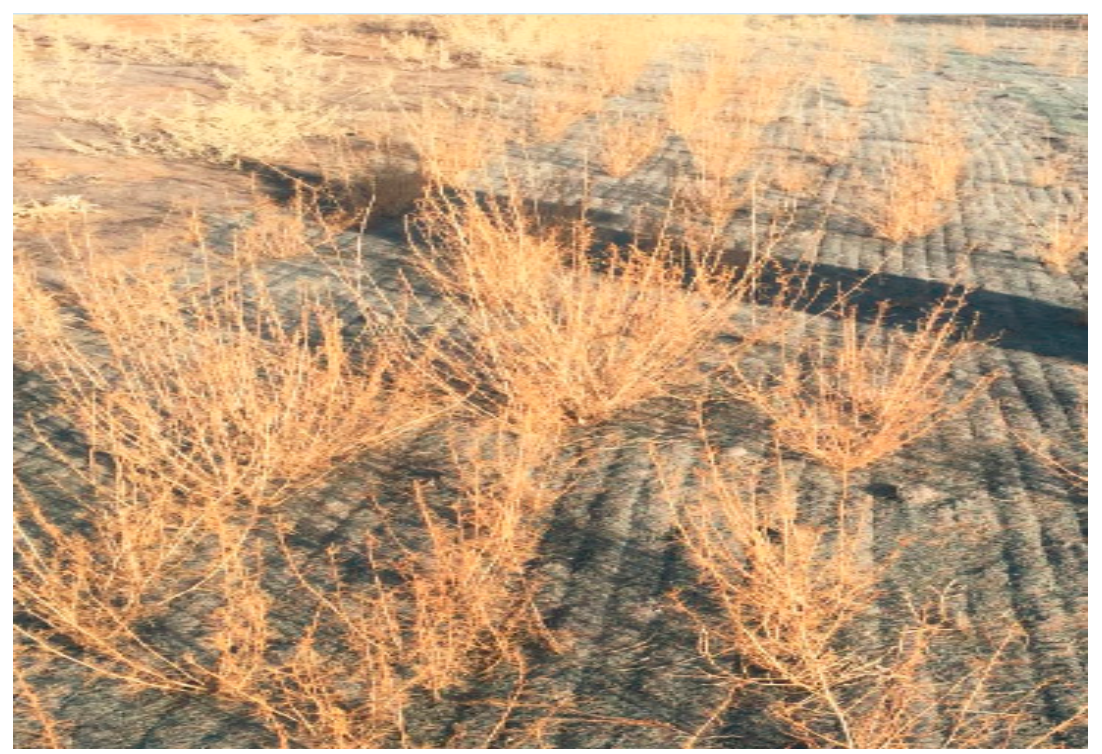


Fig. 8 The plants growth

\section{Discussion}

Palm is widely distributed in China, ranging from eastern to southwestern China, which provides sufficient source of palm fiber. At present, the price of the palm mat geotextile is about $3 \mathrm{RMB}$ per square meter including materials, transportation and construction costs. in the Hobq Desert, but the high-banded salix psammophila sand-barriers which is widely used in the Hobq Desert costs about 3.5 RMB per square meter, Moreover, the sand fixing effect of the palm mat geotextile is better than that of high-banded salix psammophila sand-barriers. With the progress of production technology, the price of the palm mat geotextile will continue to decline, which is conducive to popularization and application in large areas.

Considering the harsh environment in desert area and the characteristics of palm mat geotextile, long-term field observation and research on the stability of its structure and performance, disintegration cycle and the impact on plant growth are needed in the future.

\section{Conclusions}

Generally speaking, the physical performance test showed that the palm mat geotextile had great flexibility and tensile strength, completely covered sand dunes and without any breakage after one year. The immersion experiment showed that the palm mat geotextile had good water permeability, saturated water content and structure stability after the heavy rain. The field experiment illustrated that cooling effect in summer, heat preservation in winter, and the excellent resistance to wind erosion of the palm mat geotextile made it as good sand fixation material, which is superior to high-banded salix psammophila sand-barriers.

\section{Acknowlegements}

This work is funded by the National Science and Technology Support Program 
(2015BAC06B01-01) and Project of National Natural Science Foundation of China (41371025).

\section{References}

[1] UNCCD. (1994).United Nations convention to combat desertification in those countries experiencing serious drought and/or desertification, particularly in Africa (pp. 1-2). Geneva: United Nations Environment Programme for the Convention to Combat Desertification (CCD).

[2] Middleton,N, Thomas,D.S.G., 1997. World Atlas of Desertification. Arnold,p.182.

[3] State Forestry Administration of China. China's Fifth National bulletin on desertification and desertification [N]. China Environmental News, 2015-12-30.

[4] Wang, Tao. (2004). Progress in sandy desertification research of China, Journal of Geographical Sciences, 14(4), 387- 400.

[5] Zhu Z D, Chen G T. Sandy Desertification in China (in Chinese). Beijing: Science Press, 1994. $7-15$

[6] Wang, T., Zhu, Z., Wu, W., 2002. Sandy desertification in the north of China. Sci. China Ser.D Earth Sci. 45, 23-34.

[7] Wang, T., Wu, W., Xue, X., Sun, Q., Chen, G., 2004. Study of spatial distribution of sandy desertification in North China in recent 10 years. Sci. China Ser. D Earth Sci.47, 78-88.

[8] Wang, T., Sun, J.-G., Han, H., Yan, C.-Z., 2012. The relative role of climate change and human activities in the desertification process in Yulin region of northwest China Environ. Monit. Assess. 184, 7165-7173.

[9] Lin Yuquan, Jin Jong, Zou Bengong, et al. Effect of Fence Techniques in Leveling Sand Accumulation Around Sandbreaks-Case Study in Shapotou Distric [J]. Journal of Desert Research, 1984,4(3):16-21.(in Chinese with English abstract) 
[10] Gao Fei, Gao Yong, Gao Qiang, et al. Effects of Salix psammophila Checkboard of Physical and Characteristics of Sandy Soil [J]. Journal of Inner Mongolia Agricultural University,2006,27(2):39-42. (in Chinese with English abstract)

[11] Li Xiaoyan, Liu Lianyou, Gong Jiadong. Influence of pebble mulch on soil erosion by wind and trapping capacity for windblown sediment[J]. Soil \& Tillage Research, 2001, 59: $137-142$

[12] Tan Lihai. Effect of Gravel Mulch on Soil and Water Conversation_—A Case Study in the Northern Edge of Hobq Desert [J]. Research of Soil and Water Conservation, 2017, 24(6): 172-178. (in Chinese with English abstract)

[13] Wang Wanfu, WangTao, Fan Jjinshi, et al. Effect of Nylon Net Fence on Preventing Blown Sand at Top of Mogao Grottoes, Dunhuang[J]. Journal of Desert Research, 2005,25(5):640-648. (in Chinese with English abstract)

[14] Qu Jianjun,Yu Wenbo,Qin Xiaobo. Wind-protecting Efficiency of HDPE Functional Sand-fixing Barriers[J]. Journal of Desert Research, 2014,34(5) :1185-1193. (in Chinese with English abstract)

[15] Tong Wei, Han Jichang, Wang Huanyuan, et al.Sand-fixing Effect of Compound Soil by Mixing Feldspathic Sandstone and Sand in the Mu Us Sand Land [J]. Journal of Desert Research, 2015,35(6):1467-1472. (in Chinese with English abstract)

[16] Liu Hujin, Yuan Hongbo, Guo Chunxiu, et al. Windbreak Efficiency of Two Types of Simulated Shrub Forest Equally Planted in Field [J]. Journal of Desert Research, 2015,35(1):8-13. (in Chinese with English abstract)

[17] Sun Tao, Liu Hujin, Zhu Guoqin, et al. Timeliness of Reducing Wind and Stabilizing Sand Functions of Three Mechanical Sand Barriers in Arid Region [J]. Journal of Soil and Water Conservation, 2012,26(4):13(in Chinese with English abstract)

[18] Xie Shengbo, Qun Jianjun, Pang Yinjun, et al. Causes and Controlling Mode of Sand Hazards in Honglainghe Section of Qinghai-Tibet Railway [J]. Journal of the China Railway Society,2014,36(11):99-105(in Chinese with English abstract) 
[19] Lu Ruijie, Liu Xiaokang, Lin Jinfeng, et al. Effects of Typical Sand-Fixing Plant on Soil Improvement in Qinhai Lake Area [J] Journal of Soil and Water Conservation, 2015,39(4):177-181(in Chinese with English abstract)

[20] Ding Qinjun, Xu Xiangjun, Chen Youzhi, et al. The Research Advances of Chemical Sand-fixing Materials [J]. Journal of Wuhan University of Technology, 1980(1):33-37(in Chinese with English abstract)

[21] Han Zhiwen, $\mathrm{Hu}$ Yingdi, Chen Guangting, et al. The Suitability of Chemical Engineering Stabilization in Controlling Aeolian Hazard Along the Highway in Tarim Basin[ J] .Environment Science, 2000,21(5): 86-88. (in Chinese with English abstract)

[22] Bhattacharyya R, Fullen M A,Booth C,et al. Effectiveness of biological geotextiles for soil and water conservation in different agro-environments [J].Land Degradation \& Development, 2011,22(5)495-504

[23] Dembicki E, Niespodzinska L, Geotextiles in coastal engineering practice[J].Geo textiles and geomembranes, 1991,10(2):147-159

[24] Han Luo,Zhao Tingning, Mei Dong, et al. Field studies on the effects of three geotextiles on runoff and erosion of road slope in Beijing, China[J].Catena, 2013,109:150-156

[25] J. Álvarez-Mozos, E. Abad, M. Goñi, et al. Evaluation of erosion control geotextiles on steep slopes. Part 2: Influence on the establishment and growth of vegetation[J]. Catena 2014,121:195-203

[26] Ding Chaohua, Kang Ning, Wu Xianwei, et al Research on the soilless Turfgrass Mat Production [J]. Journal of Wuhan Botanical Research 1994,12(3):263-269.(in Chinese with English abstract)

[27] Rickson R J, Controlling sediment at source an evaluation of erosion control geotextiles [J].Earth Surface Processes and Landforms, 2006,31(5) :550-560.

[28] Smets T, Poesen J, Bhattacharyya R, et al. Evaluation of Biological Geotextiles for Reducing Runoff and Soil Loss under Various Environment Conditions Using Laboratory and Field Plot Data[J].Land Degradation \&Development, $2011,22(5): 480-494$. 
[29] Smets T, Poesen J, Langhans C, et al. Concentrated flow erosion rates reduced through biological geotextiles [J].Earth Surface Processes and Landforms, 2009,34(4):493-502.

[30] Bhattacharyya R, Fullen M, Davies K,et al Use of palm-mat geotextiles for rainsplash erosion control[J].Geomophology, 2010,119(1/2):52-61

[31] Bhattacharyya R, Davies K, Fullen M, et al Effects of palm mat geotextiles on the conservation of loamy sand soils in east Shropshire[J].Advances in GeoEcology, 2008, 39,527-538

[32] Smets T, Poesen J. Effectiveness of palm and simulated geotextiles in reducing run-off and inter-rill erosion on medium and steep slopes[J].Soil Use and Management, $2007,23(3): 306-316$.

[33] Wang YC, Feng XW, Wang LP, Zhao HC. The effect of a reservoir on the siltation of the Inner Mongolian Reach of the Yellow River[J].Yellow River 1996,1:5 -10.

[34] Chen Wenxue, Tan Shuiwei, Bai Yinbaoligao, et al. Study on anti-erosion characteristics of KLD grass carpet[J]. Water Resources and Hydropower Engineering,2015,46(4):152-155 